\title{
Dysfunctional lung anatomy and small airways degeneration in COPD
}

This article was published in the following Dove Press journal:

International Journal of COPD

3 January 2013

Number of times this article has been viewed

\section{Clémence Martin \\ Justine Frija \\ Pierre-Régis Burgel}

Department of Respiratory Medicine, Cochin Hospital, AP-HP and Université Paris Descartes, Sorbonne Paris Cité, Paris, France
Correspondence: Pierre-Régis Burgel Service de Pneumologie, Hôpital Cochin, 27 rue du Faubourg Saint Jacques,

75014 Paris, France

Tel +33I 584I 2367

Fax +33। 46338253

Email pierre-regis.burgel@cch.aphp.fr

\begin{abstract}
Chronic obstructive pulmonary disease (COPD) is characterized by incompletely reversible airflow obstruction. Direct measurement of airways resistance using invasive techniques has revealed that the site of obstruction is located in the small conducting airways, ie, bronchioles with a diameter $<2 \mathrm{~mm}$. Anatomical changes in these airways include structural abnormalities of the conducting airways (eg, peribronchiolar fibrosis, mucus plugging) and loss of alveolar attachments due to emphysema, which result in destabilization of these airways related to reduced elastic recoil. The relative contribution of structural abnormalities in small conducting airways and emphysema has been a matter of much debate. The present article reviews anatomical changes and inflammatory mechanisms in small conducting airways and in the adjacent lung parenchyma, with a special focus on recent anatomical and imaging data suggesting that the initial event takes place in the small conducting airways and results in a dramatic reduction in the number of airways, together with a reduction in the cross-sectional area of remaining airways. Implications of these findings for the development of novel therapies are briefly discussed.
\end{abstract}

Keywords: emphysema, small airways disease, airway mucus, innate immunity, adaptive immunity

\section{Introduction}

Chronic obstructive pulmonary disease (COPD) is characterized by persistent and usually progressive airflow limitation. ${ }^{1}$ In genetically susceptible individuals, inhaled noxious particles and gases induce an enhanced inflammatory response in the airways and result in structural changes (a process often referred to as "remodeling") in airways and in lung parenchyma. Although COPD is associated with exacerbations and comorbidities that contribute to the overall severity in selected patients, the present article focuses on structural abnormalities and inflammation in the lung compartment under stable conditions. Our goal is to examine potential mechanisms leading to these structural abnormalities at the site of airflow limitation, ie, the small conducting airways. Importantly, most of the data presented here were obtained in (ex) smokers. These data are relevant to the pathophysiology of cigarette smoke-induced COPD, but it is unclear at this time whether they also apply to COPD triggered by other environmental exposures (eg, exposure to biomass). ${ }^{2}$

\section{Anatomical considerations}

In humans, the lower conducting airways arise from the trachea and divide into 8-25 generations, depending on the length of the pathway followed ${ }^{3}$ down to 
the terminal bronchioles (the smallest airways without alveoli) and respiratory bronchioles, which open into the gas-exchange apparatus (the alveoli). ${ }^{4}$ Small (conducting) airways are usually defined as airways without cartilage and with an internal diameter $<2 \mathrm{~mm}$. These airways are located from approximately the eighth generation of airway to the respiratory bronchioles. In normal individuals, the cross-sectional area of the airways increases rapidly from a total of $2.5 \mathrm{~cm}^{2}$ in the trachea to approximately $180 \mathrm{~cm}^{2}$ at the level of the terminal bronchioles. Resistance to airflow in a tube (or an airway) varies inversely with the fourth power of the radius, and resistance to airflow in parallel tubes (or in branching airways) varies inversely with the fourth power of the total cross-sectional area. These calculations explain why most of the resistance to airflow in healthy humans is located in the proximal airways (above the sixth division), and why small conducting airways account for less than $10 \%$ of airway resistance.

\section{Site of airflow limitation: a long search for small airways}

Direct measurement of airways resistance in small airways using the wedge bronchoscope technique has revealed that small airways resistance is multiplied by $4-40$ in patients with COPD, indicating that small conducting airways are the main site of airflow limitation in patients with the disease. ${ }^{5,6}$ Although some of the relevant experiments were reported more than 40 years ago, ${ }^{5}$ understanding of the mechanisms of increased small airways resistance in patients with COPD has been relatively slow. Measurement of small airways dysfunction in living individuals remains a challenge, and progress in this area has been impeded by technical limitations related to the small size of these airways and to their location deep within the thoracic cavity. Firstly, because obstruction of a single small airway results in very little change in the cross-sectional area of all small airways, abnormalities in numerous small airways may occur without any change in conventional pulmonary function tests, eg, forced expiratory volume in one second $\left(\mathrm{FEV}_{1}\right){ }^{7}$ Secondly, the spatial resolution on computed tomography (CT) scan (the most widely available lung tool to examine lung anatomy) is around $0.6-1 \mathrm{~mm}$, which allows direct assessment of medium-sized airways (diameter $>2-2.5 \mathrm{~mm}$ ), but not of smaller airways. Thus, investigators have had to rely on indirect assessment of the small airways by measuring areas of mosaic lung attenuation or air trapping (on inspiratory and expiratory CT scans, respectively) or by using sophisticated physiological measurements (eg, nitrogen washout tests, impulse oscillometry) of small airways dysfunction. These indirect measurements have some usefulness in the clinical setting, but have failed to provide significant insight into the mechanisms of small airways dysfunction. Most progress in this area has been made using pathological information and more recently using very high-resolution imaging techniques (eg, micro-CT) ex vivo.

\section{Anatomical changes in small conducting airways}

Small conducting airways appear to be the site of airflow limitation in COPD, and the increase in expiratory resistance to airflow implies a reduction in the total cross-sectional area of the small airways. Theoretically, the reduction in cross-sectional area of the small airways may be related to a decrease in the number of small airways and/or a reduction in the cross-sectional area of a large number of individual small airways. Based on these calculations, it appears important to examine both the number of small airways and the structural abnormalities in the small airways of patients with COPD. The number of small airways in the lungs of patients with COPD has proven difficult to establish because principles of unbiased stereology indicate that counting numbers of threedimensional structures requires knowledge of the reference volume of the tissue analyzed, ${ }^{8}$ which is difficult to determine using histological studies. Progress in lung imaging allows determination of lung volume from volumetric high-resolution CT scans. High-resolution CT also allows visualization and reconstruction of the airways, but its spatial resolution remains inappropriate for analysis of the small airways (see above). Investigators have used high-resolution CT scans to examine the number of medium-sized airways (as a surrogate marker for small-sized airways) in patients with COPD. ${ }^{9,10}$ McDonough et al studied 58 high-resolution CT scans from patients with COPD GOLD (Global Initiative for Chronic Obstructive Lung Disease) stage 1-4 and compared them with those of 20 smokers with normal lung function matched for age and smoking history. ${ }^{10}$ They found reduced numbers of medium-sized airways (internal diameter 2-2.5 mm) in patients with COPD GOLD stage 1 and 2 as compared with smokers who have normal lung function. The reduction in numbers of medium-sized airways was even more pronounced in GOLD stage 3 and 4 patients. ${ }^{10}$ These data suggested that destruction of the small conducting airways is an important feature in patients with COPD, although it is still possible that medium-sized airways had undergone shrinkage and could not be identified on CT scans due to their smaller size. Micro-CT is an imaging technique with higher spatial resolution than 
conventional high-resolution $\mathrm{CT}$, but can be performed only on resected lung (ex vivo) due to the use of tissue-damaging levels of radiation. Use of micro-CT on a limited number of lung tissues enabled a comparison of the number of terminal bronchioles in the explanted lungs from eight patients with severe airflow limitation and centrilobular or panlobular emphysema with those obtained in four control lungs. ${ }^{10}$ The number of terminal bronchioles was reduced by ten-fold in subjects with centrilobular emphysema and by four-fold in subjects with panlobular emphysema. Furthermore, the authors measured the cross-sectional area of terminal bronchioles and found a marked reduction (up to 100-fold) in subjects with severe airflow limitation, suggesting that reduced crosssectional area was related to both destruction of small airways and to a reduction in the cross-sectional area of remaining airways. The mechanisms leading to destruction of the small airways in patients with COPD have not yet been established, but the histological characteristics of small airways have been described in detail.

Hogg et al studied the relationship between airflow limitation (as assessed by $\mathrm{FEV}_{1}$ ) and histological findings in a series of lung tissues surgically removed from subjects with COPD GOLD stage $1-4(\mathrm{n}=159) .{ }^{11}$ The authors found that a lower $\mathrm{FEV}_{1}$ was associated with an increased volume of tissue in the walls of the small airways and with accumulation of mucous exudates in the small airways lumen. ${ }^{11}$ Epithelial abnormalities, including epithelial proliferation, squamous metaplasia, ${ }^{7,12}$ and goblet cell hyperplasia, ${ }^{13}$ likely contribute to narrowing of the small airways lumina via an increase in wall thickness. Peribronchiolar fibrosis is also an important feature responsible for small airways narrowing in patients with COPD. ${ }^{7,14}$ Accumulation of mucous exudates within the lumen of small conducting airways further aggravates the airflow limitation. ${ }^{11,15}$ Interestingly, squamous metaplasia promotes peribronchiolar fibrosis, ${ }^{12}$ and mucins secreted from airway epithelial goblet cells ${ }^{13,15}$ contribute to accumulation of mucous exudates in the airway lumen, pointing towards the airway epithelium as a major target for therapeutic intervention. It is suggested that these structural changes in small conducting airways are related to repair mechanisms aiming to protect the small airways from destruction by repeated insults from cigarette smoke.

\section{Emphysema}

Emphysema is defined by "abnormal, permanent enlargement of airspace distal to the terminal bronchiole, accompanied by the destruction of their walls, and without obvious fibrosis". ${ }^{16}$ Destruction of the alveolar wall has long been assumed to result from proteolytic degradation due to an altered protease/ antiprotease imbalance. ${ }^{17}$ This concept was based on the description of emphysema in alpha1-antitrypsin deficiency ${ }^{18}$ and on development of animal models of emphysema through intratracheal instillation of proteases (pancreatic or neutrophil elastase). ${ }^{19}$ In recent years, the concept has emerged that destruction of the alveolar wall may also occur as a result of a failure of lung maintenance and repair programs, which are required in response to repeated injury caused by cigarette smoke. ${ }^{20}$ Thus, increased levels of apoptosis and proliferation of alveolar epithelial cells have been reported in patients with emphysema. ${ }^{21,22}$ The ability of alveolar cells to proliferate is a limited process, because repeated cell cycles may cause senescence, which has been reported in both epithelial and endothelial cells in the alveoli of patients with emphysema. ${ }^{23}$ A possible contribution of autoimmunity to the pathophysiology of emphysema has been suggested. ${ }^{24-26}$ Lee et al reported that an autoimmune response to elastin fragment involving $\mathrm{T}$ and $\mathrm{B}$ cell-mediated immunity against elastin was associated with emphysema. ${ }^{27}$ However, other studies did not find evidence for an autoimmune response against elastin..$^{28,29}$ At this point, it is unclear whether autoimmunity is implicated in the pathogenesis of emphysema. Representative photomicrographs of small airway abnormalities and emphysema are presented in Figure 1.

\section{Relationship between small airway abnormalities and emphysema}

The classic understanding of the relationship between small airways disease and emphysema involves loss of alveolar attachment, which destabilizes the bronchioles due to loss of elastic recoil. In this scenario, alveolar destruction comes first and promotes premature airway closure during expiration. ${ }^{30}$ However, the sequence of events that leads from smoking exposure to structural abnormalities in the small conducting airways and adjacent alveoli that are found in patients with COPD remains speculative. ${ }^{30}$ An interesting hypothesis, which had been presented recently, suggests that narrowing and disappearance of small conducting airways occurs before the onset of emphysematous destruction. ${ }^{10}$ In this model, emphysema may result from loss of support at the distal acinus by terminal bronchioles, leading to collapse and folding of the alveolar walls. ${ }^{30}$ This hypothesis is based on histological data presented by McDonough et al; when these authors examined the numbers and thickness of terminal bronchioles in relation to the mean linear intercept (a marker of emphysema), they found that before emphysema can be detected microscopically, terminal bronchioles are 


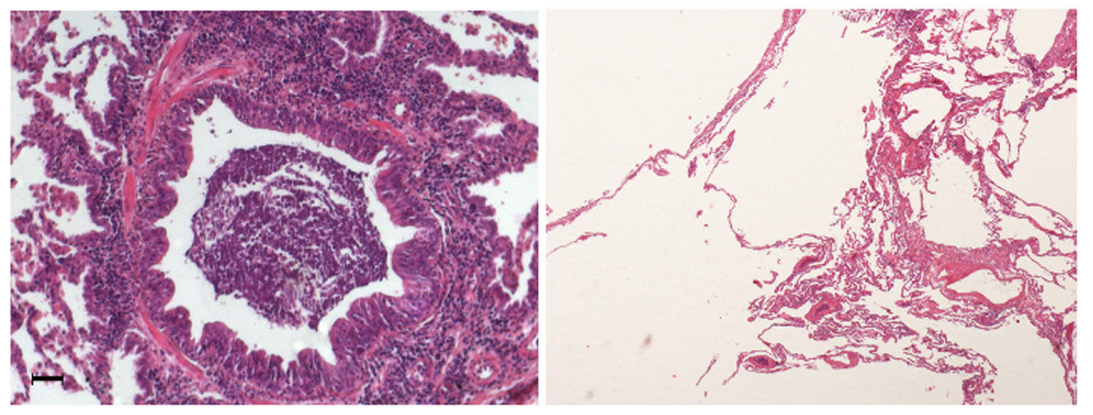

Figure I Representative photomicrograph of small airways disease and emphysema in a patient with chronic obstructive pulmonary disease.

Notes: The small airway (left panel) is characterized by obstruction of the lumen by mucous exudate. Also note the markedly thickened airway wall with recruitment of numerous inflammatory cells. In the right panel, emphysema is characterized by destruction of alveolar walls without enlargement of airspace, and without obvious fibrosis. Bar $30 \mu \mathrm{m}$.

reduced in numbers and those that remain had thickened airway walls. ${ }^{10}$

A recent study by Galban et al examined high-resolution CT scans in a cohort of 194 subjects with COPD using parametric response mapping (PRM), a new voxel-wise image analysis technique, that enables differentiation of functional small airways disease (fSAD) from emphysema by analyzing individual voxels in inspiratory and expiratory CT scans. ${ }^{31}$ The authors found that PRM ${ }^{\mathrm{FAD}}$ can be detected in subjects with minimal emphysema, and that both emphysema and

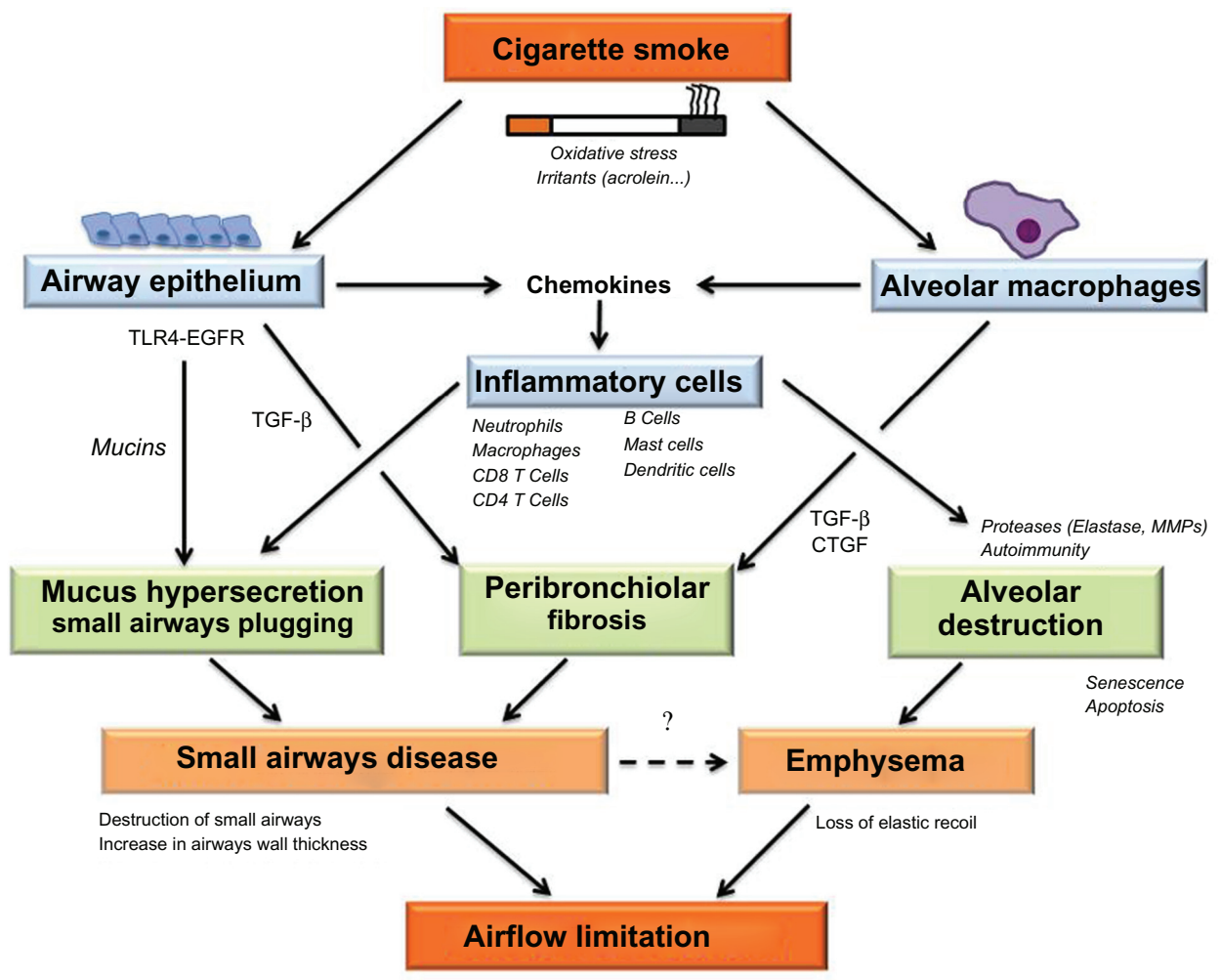

Figure 2 Diagram depicting potential mechanisms leading to airflow limitation via structural abnormalities in the small conducting airways and alveoli.

Notes: Cigarette smoke, a source of oxidative stress and irritants, is recognized by airway epithelial cells and alveolar macrophages. Secretion of chemokines by resident cells induces recruitment of inflammatory cells in the airways and alveoli. ${ }^{33}$ Recognition of cigarette smoke by the airway epithelium involves TLR-4 and leads to the activation of EGFR, resulting in mucus production in epithelial goblet cells. ${ }^{46}$ Neutrophil proteases (eg, elastase) activate the degranulation of goblet cells, ${ }^{48}$ contributing to formation of mucous exudates within the lumen of the small airway. The repair response in small airways also involves thickening of the airway walls, at least in part related to peribronchial fibrosis. Activation of fibrosis in peribronchiolar mesenchymal cells is related to secretion of profibrotic growth factors (eg, TGF- $\beta$ and CTGF) released by the airway epithelium and by alveolar macrophages. ${ }^{12,33}$ Small airways disease, characterized by an increase in airway wall thickness and mucous exudates in the lumen," and by destruction of the small airways, ${ }^{10}$ contributes to reduction in the cross-sectional area of the small airways, leading to airflow limitation. Alveolar destruction, which characterizes emphysema, may be related to proteolytic destruction of alveolar walls and/or to the failure of lung maintenance and repair programs involving apoptosis, senescence, and autoimmunity. ${ }^{20}$ Emphysema promotes airway closure during expiration, contributing to airflow limitation via loss of elastic recoil. Recent data also suggest that destruction of the small airways may promote emphysema via loss of support at the distal acinus. ${ }^{10,30}$

Abbreviations: EGFR, epidermal growth factor receptor; TGF- $\beta$, transforming growth factor; TLR-4, toll-like receptor-4; CTGF, connective tissue growth factor; MMPs, matrix metalloproteinases. 
fSAD contribute to airflow limitation in subjects with severe airflow limitation. ${ }^{31}$ Although both studies point toward the same attractive hypothesis, they had a cross-sectional design and the suggestion that small airways disease occurs before emphysematous destruction will require confirmation obtained in longitudinal studies. Although the pathological correlates of PRM ${ }^{\mathrm{ISAD}}$ will need to be established, the use of PRM may allow for such a study design in living individuals.

\section{Inflammatory cells and mediators: relationship with structural abnormalities}

Cigarette smoke triggers an inflammatory response in the airway epithelium of the proximal and distal bronchi, in the alveoli, and in the pulmonary arteries. ${ }^{32}$ Recruitment of inflammatory cells in the airways and alveoli involves the secretion of chemokines by resident cells (eg, epithelial cells and alveolar macrophages) in response to cigarette smoke. ${ }^{33}$ Initial studies have identified phagocytes (eg, neutrophils and macrophages), which are part of the innate immune system, in the small airways and alveoli of both smokers and COPD subjects. ${ }^{34}$ The contribution of the adaptive immune system to the pathogenesis of COPD was later described. ${ }^{35}$ In particular, CD4+ and CD8+ T lymphocytes were found in small conducting airways and in the alveoli, ${ }^{36-38}$ and tertiary lymphoid structures (also called lymphoid follicles) containing B and $\mathrm{T}$ lymphocytes were reported around the small airways in subjects with severe airflow limitation. ${ }^{11}$ Dendritic cells are antigen-presenting cells which link the innate and adaptive immune systems. Recent studies have revealed that dendritic cell numbers are increased in the epithelium and adventitia of small conducting airways in subjects with $\mathrm{COPD}^{39}$ and have suggested that dendritic cell maturation is associated with the severity of airflow limitation. ${ }^{40}$ Eosinophils have been found in the airways during exacerbations of COPD, especially in the context of viral infection. ${ }^{41}$ More recently, mast cells have been identified in small airways smooth muscle and in alveoli. ${ }^{42,43}$ Mechanisms of recruitment and activation of these inflammatory cells have been discussed elsewhere. ${ }^{33,35}$

Airways inflammation and remodeling both occur in the lungs of patients with COPD, and it is likely that inflammation contributes to the structural abnormalities. However, evidence linking these processes remains scarce. Loss of alveolar attachment in small conducting airways is correlated with leukocyte recruitment, suggesting a role for proteases secreted by leukocytes in this process. ${ }^{44} \mathrm{CD} 8+\mathrm{T}$ cells ${ }^{45}$ and neutrophils ${ }^{13}$ have been correlated with goblet cell hyperplasia in small conducting airway epithelium, suggesting that these cells contribute to hypersecretion of mucus. ${ }^{46} \mathrm{CD} 8+\mathrm{T}$ cells were also found in the alveoli, where they were suggested to contribute to alveolar destruction via release of proteolytic enzymes (eg, granzymes and perforins). ${ }^{47}$ Increased numbers of mast cells have been found in the alveoli in centrilobular emphysema, but not in panlobular emphysema, suggesting a distinct role in the pathogenesis of centrilobular emphysema. ${ }^{43}$ These findings suggest that therapies targeting inflammatory cell recruitment and/or activation may result in improvement in structural abnormalities, but this concept will require confirmation when appropriate drugs become available for clinical trials.

\section{Conclusion}

Small airways with an internal diameter $<2 \mathrm{~mm}$ represent the site of airflow limitation in patients with COPD. Abnormalities in the small airways include airway wall thickening due to epithelial modifications and to peribronchiolar fibrosis, and obstruction of small airway lumina by mucous exudates. Recent studies indicate that the number of small airways is reduced in subjects with COPD and suggest that small airways destruction may occur before emphysema. The pathogenesis of emphysema includes a protease/ antiprotease imbalance and failure of lung maintenance and repair programs that may involve apoptosis, senescence, and autoimmunity. Airway inflammation by phagocytes (neutrophils, macrophages) and lymphocytes (especially CD8+ T lymphocytes) likely contributes to structural abnormalities in small airways and emphysema.

\section{Implications for treatment}

The airflow limitation characteristic of COPD occurs as a result of structural abnormalities in the small conducting airways and alveoli. The potential mechanisms leading to airflow limitation via structural abnormalities in the small conducting airways and alveoli is shown in Figure 2. Recent data suggest that the initial event leading to airflow limitation occurs in the small conducting airways, where inflammatory cells are recruited. Remodeling of the small conducting airways presumably occurs as a repair mechanism after epithelial injury but results in destruction of small airways, thickening of the airway wall, and hypersecretion of mucus in the small airways, promoting airflow limitation. Emphysema also promotes airflow limitation due to loss of elastic recoil of the small airways, but recent data also suggest that small airways disease may promote emphysema. Although some of these findings will 
require confirmation in future longitudinal studies, the current evidence indicates that therapeutic intervention should be initiated as early as possible to prevent destruction of small conducting airways and emphysema. Smoking cessation is obviously the first therapeutic intervention, but is insufficient alone due to a self-perpetuating inflammatory and remodeling process in the airways. The effects of current therapies (eg, bronchodilators and inhaled steroids) on structural abnormalities in patients with COPD are unclear, but presumably limited. It is likely that novel therapies aimed at reducing airway inflammation and remodeling should be developed. These therapies would be optimally delivered by inhalation, which may then limit systemic side effects. Conventional inhaled therapies may not deposit in small airways owing to their granulometry, being composed of 3-5 $\mu \mathrm{m}$ particles which deposit mostly in the large airways. Targeting distal airways in COPD may be achieved by systemic administration of drugs and/or by using extra-fine particles, which deposit in both the proximal and distal airways. Future studies aimed at developing treatments for lung disease in COPD should take these findings into consideration.

\section{Acknowledgment}

The authors thank Professor Diane Damotte from the Department of Pathology, Université Paris Descartes, for providing photomicrographs of lung sections from a patient with COPD.

\section{Disclosure}

The authors report no conflicts of interest in this work.

\section{References}

1. Vestbo J, Hurd SS, Agusti AG, et al. Global strategy for the diagnosis, management and prevention of chronic obstructive pulmonary disease. Am J Respir Crit Care Med. August 9, 2012. [Epub ahead of print.]

2. Salvi SS, Barnes PJ. Chronic obstructive pulmonary disease in nonsmokers. Lancet. 2009;374:733-743.

3. Horsfield K, Cumming G. Morphology of the bronchial tree in man. J Appl Physiol. 1968;24:373-383.

4. Burgel PR. The role of small airways in obstructive airway diseases. Eur Respir Rev. 2011;20:23-33.

5. Hogg JC, Macklem PT, Thurlbeck WM. Site and nature of airway obstruction in chronic obstructive lung disease. NEngl J Med. 1968;278: 1355-1360.

6. Yanai M, Sekizawa K, Ohrui T, Sasaki H, Takishima T. Site of airway obstruction in pulmonary disease: direct measurement of intrabronchial pressure. J Appl Physiol. 1992;72:1016-1023.

7. Cosio M, Ghezzo H, Hogg JC, et al. The relations between structural changes in small airways and pulmonary-function tests. $N$ Engl J Med. 1978;298:1277-1281.

8. Howard CV, Reed MG, editors. Unbiased Stereology. Three-Dimensional Measurement In Microscopy. Oxford, UK: BIOS Scientific Publishers Limited; 1998.

9. Diaz AA, Valim C, Yamashiro T, et al. Airway count and emphysema assessed by chest $\mathrm{CT}$ imaging predicts clinical outcome in smokers. Chest. 2010;138:880-887.
10. McDonough JE, Yuan R, Suzuki M, et al. Small-airway obstruction and emphysema in chronic obstructive pulmonary disease. $N$ Engl $\mathrm{J}$ Med. 2011;365:1567-1575.

11. Hogg JC, Chu F, Utokaparch S, et al. The nature of small-airway obstruction in chronic obstructive pulmonary disease. $N$ Engl J Med. 2004;350:2645-2653.

12. Araya J, Cambier S, Markovics JA, et al. Squamous metaplasia amplifies pathologic epithelial-mesenchymal interactions in COPD patients. J Clin Invest. 2007;117:3551-3562.

13. Saetta M, Turato G, Baraldo S, et al. Goblet cell hyperplasia and epithelial inflammation in peripheral airways of smokers with both symptoms of chronic bronchitis and chronic airflow limitation. Am J Respir Crit Care Med. 2000;161:1016-1021.

14. Mitchell RS, Stanford RE, Johnson JM, Silvers GW, Dart G, George MS. The morphologic features of the bronchi, bronchioles, and alveoli in chronic airway obstruction: a clinicopathologic study. Am Rev Respir Dis. 1976;114:137-145.

15. Caramori G, Di Gregorio C, Carlstedt I, et al. Mucin expression in peripheral airways of patients with chronic obstructive pulmonary disease. Histopathology. 2004;45:477-484.

16. Snider GL, Kleinerman J, Thurlbeck WM, Bengali ZH. The definition of emphysema: report of a National Heart, Lung, and Blood Institute workshop. Am Rev Respir Dis. 1985;132:182-185.

17. MacNee W. Pathogenesis of chronic obstructive pulmonary disease. Proc Am Thorac Soc. 2005;2:258-266.

18. Stoller JK, Aboussouan LS. Alpha1-antitrypsin deficiency. Lancet. 2005;365:2225-2236.

19. Snider GL, Sherter CB. A one-year study of the evolution of elastaseinduced emphysema in hamsters. J Appl Physiol. 1977;43:721-729.

20. Tuder RM, Petrache I. Pathogenesis of chronic obstructive pulmonary disease. J Clin Invest. 2012;122:2749-2755.

21. Imai K, Mercer BA, Schulman LL, Sonett JR, D'Armiento JM. Correlation of lung surface area to apoptosis and proliferation in human emphysema. Eur Respir J. 2005;25:250-258.

22. Yokohori N, Aoshiba K, Nagai A. Increased levels of cell death and proliferation in alveolar wall cells in patients with pulmonary emphysema. Chest. 2004;125:626-632.

23. Tsuji T, Aoshiba K, Nagai A. Alveolar cell senescence in patients with pulmonary emphysema. Am J Respir Crit Care Med. 2006;174: 886-893.

24. Cosio MG, Saetta M, Agusti A. Immunologic aspects of chronic obstructive pulmonary disease. $N$ Engl J Med. 2009;360:2445-2454.

25. Agustí A, MacNee W, Donaldson K, Cosio M. Hypothesis: does COPD have an autoimmune component? Thorax. 2003;58:832-834.

26. Taraseviciene-Stewart L, Scerbavicius R, Choe KH, et al. An animal model of autoimmune emphysema. Am J Respir Crit Care Med. 2005;171:734-742.

27. Lee SH, Goswami S, Grudo A, et al. Antielastin autoimmunity in tobacco smoking-induced emphysema. Nat Med. 2007;13:567-569.

28. Rinaldi M, Lehouck A, Heulens N, et al. Antielastin B-cell and T-cell immunity in patients with chronic obstructive pulmonary disease. Thorax. 2012;67:694-700.

29. Greene CM, Low TB, O'Neill SJ, McElvaney NG. Anti-proline-glycineproline or antielastin autoantibodies are not evident in chronic inflammatory lung disease. Am J Respir Crit Care Med. 2010;181:31-35.

30. Mitzner W. Emphysema - a disease of small airways or lung parenchyma? N Engl J Med. 2011;365:1637-1639.

31. Galbán CJ, Han MK, Boes JL, et al. Computed tomography-based biomarker provides unique signature for diagnosis of COPD phenotypes and disease progression. Nat Med. 2012;18:1711-1715.

32. Burgel PR, Bourdin A, Chanez P, et al. Update on the roles of distal airways in COPD. Eur Respir Rev. 2011;20:7-22.

33. Barnes PJ. The cytokine network in chronic obstructive pulmonary disease. Am J Respir Cell Mol Biol. 2009;41:631-638.

34. Saetta M, Turato G, Maestrelli P, Mapp CE, Fabbri LM. Cellular and structural bases of chronic obstructive pulmonary disease. Am J Respir Crit Care Med. 2001;163:1304-1309. 
35. Brusselle GG, Joos GF, Bracke KR. New insights into the immunology of chronic obstructive pulmonary disease. Lancet. 2011;378: 1015-1026.

36. Lams BE, Sousa AR, Rees PJ, Lee TH. Immunopathology of the smallairway submucosa in smokers with and without chronic obstructive pulmonary disease. Am J Respir Crit Care Med. 1998;158:1518-1523.

37. Saetta M, Baraldo S, Corbino L, et al. CD8+ve cells in the lungs of smokers with chronic obstructive pulmonary disease. Am J Respir Crit Care Med. 1999;160:711-717.

38. Saetta M, Di Stefano A, Turato G, et al. CD8+ T-lymphocytes in peripheral airways of smokers with chronic obstructive pulmonary disease. Am J Respir Crit Care Med. 1998;157:822-826.

39. Demedts IK, Bracke KR, Van Pottelberge G, et al. Accumulation of dendritic cells and increased CCL20 levels in the airways of patients with chronic obstructive pulmonary disease. Am J Respir Crit Care Med. 2007;175:998-1005.

40. Freeman CM, Martinez FJ, Han MK, et al. Lung dendritic cell expression of maturation molecules increases with worsening chronic obstructive pulmonary disease. Am J Respir Crit Care Med. 2009;180: 1179-1188.

41. Papi A, Bellettato CM, Braccioni F, et al. Infections and airway inflammation in chronic obstructive pulmonary disease severe exacerbations. Am J Respir Crit Care Med. 2006;173:1114-1121.
42. Andersson CK, Mori M, Bjermer L, Lofdahl CG, Erjefalt JS. Alterations in lung mast cell populations in patients with chronic obstructive pulmonary disease. Am J Respir Crit Care Med. 2010;181: 206-217.

43. Ballarin A, Bazzan E, Hernandez Zenteno R, et al. Mast cell infiltration discriminates between histopathological phenotypes of chronic obstructive pulmonary disease. Am J Respir Crit Care Med. 2012; 186:233-239.

44. Saetta M, Ghezzo H, Kim WD, et al. Loss of alveolar attachments in smokers. A morphometric correlate of lung function impairment. Am Rev Respir Dis. 1985;132:894-900.

45. Kim V, Kelemen SE, Abuel-Haija M, et al. Small airway mucous metaplasia and inflammation in chronic obstructive pulmonary disease. COPD. 2008;5:329-338.

46. Burgel PR, Nadel JA. Epidermal growth factor receptor-mediated innate immune responses and their roles in airway diseases. Eur Respir J. 2008;32:1068-1081.

47. Vernooy JH, Moller GM, van Suylen RJ, et al. Increased granzyme A expression in type II pneumocytes of patients with severe chronic obstructive pulmonary disease. Am J Respir Crit Care Med. 2007;175: 464-472.

48. Nadel JA. Role of neutrophil elastase in hypersecretion during COPD exacerbations, and proposed therapies. Chest. 2000;117:386S-389S.
International Journal of COPD

\section{Publish your work in this journal}

The International Journal of COPD is an international, peer-reviewed journal of therapeutics and pharmacology focusing on concise rapid reporting of clinical studies and reviews in COPD. Special focus is given to the pathophysiological processes underlying the disease, intervention programs, patient focused education, and self management protocols.

\section{Dovepress}

This journal is indexed on PubMed Central, MedLine and CAS. The manuscript management system is completely online and includes a very quick and fair peer-review system, which is all easy to use. Visit http://www.dovepress.com/testimonials.php to read real quotes from published authors. 